\title{
DIÁLOGOS EM PSICOLOGIA: DISCUSSÕES CONTEMPORÂNEAS COMO DIFUSÃO CULTURAL EM DIFERENTES ESPAÇOS
}

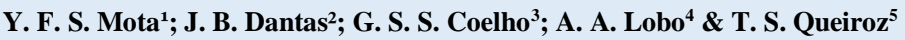

${ }^{1}$ Graduando em Psicologia pela Universidade Federal do Ceará. E-mail: yagofacanha@ gmail.com; ${ }^{2}$ Doutora pelo Programa de PósGraduação em Psicologia Social na área de História Social, Imaginário e Cultura pela Universidade Estadual do Rio de Janeiro. Professor Adjunta do Departamento de Psicologia da Universidade Federal do Ceará. Coordenadora do Laboratório de Estudos em Psicoterapia, Fenomenologia e Sociedade (LAPFES/UFC). E-mail: juremadantas@ig.com.br; ${ }^{3}$ Graduanda em Psicologia pela Universidade Federal do Ceará. E-mail:Glycias@ gmail.com; ${ }^{4}$ Graduanda em Psicologia pelo Centro Universitário UniFanor Wyden. E-mail:

lobo.alineamori@gmail.com; ${ }^{5}$ Graduanda em Psicologia pela Universidade Federal do Ceará. E-mail: talitaqueiroz.esv@ gmail.com

Artigo submetido em setembro/2018

\section{RESUMO}

Este trabalho possui o objetivo de apresentar o projeto de Extensão Diálogos em Psicologia, vinculado ao Laboratório de Estudos em Psicoterapia, Fenomenologia e Sociedade, coordenado pela Profa. Dra. Jurema Barros Dantas do Departamento de Psicologia. O Diálogos em Psicologia é voltado para a discussão das questões do contemporâneo, com problematização e troca de saberes entre os vários olhares das práticas psicológicas por meio, sobretudo, do necessário debate interdisciplinar e multiprofissional acerca dos diversos temas emblemáticos de nossa época. O projeto se iniciou em 2015 com palestras realizadas, exclusivamente, no âmbito da UFC e se expandiu a partir de 2016 em parceria com uma escolada rede pública do ensino médio suas ações. Essa extensão do projeto foi intitulada Diálogos Itinerante como uma forma de marcar, declaradamente, a proposta de promoção de espaços de reflexão crítica sobre a interface entre o saber da psicologia e as questões da atualidade que, inclusive, são promovedoras de sofrimento psíquico. Atualmente as atividades ocorrem por meio de ciclos de palestras mensais desenvolvidas ao longo do ano na UFC e neste espaço público educacional de Fortaleza. Essas ações são norteadas pelos temas gerais de pesquisa anual do laboratório, de modo a consolidar a vinculação entre ensino, pesquisa e extensão. No ano de 2018 a temática central vem sendo "Relações Amorosas", compreendendo que o panorama da "Modernidade Líquida" atravessa o fenômeno do amar, assim como a própria configuração dos relacionamentos na atualidade. Ressalta-se a necessidade de fomentar tais práticas como inclusão social e difusão cultural, mantendo laços mais estreitos com a sociedade.

PALAVRAS-CHAVE: Diálogos. Cultura. Contemporaneidade. Inclusão Social.

\section{DIALOGUE IN PSYCHOLOGY: CONTEMPORARY DISCUSSIONS AS CULTURAL DISSEMINATION IN DIFFERENT AREAS}

\begin{abstract}
This work aims to present the project Dialogues Extension in Psychology, linked to the Laboratory of Studies in Psychotherapy, Phenomenology and Society, coordinated by Profa. Dr. Jurema Barros Dantas from the Department of Psychology. Dialogues in Psychology is focused on the discussion of contemporary issues, with problematization and exchange of knowledge between the various perspectives of psychological practices, mainly through the necessary interdisciplinary and multiprofessional debate on the various emblematic themes of our time. The project began in 2015 with lectures held exclusively within the scope of the UFC and expanded from 2016 in partnership with a public high school schooled its actions. This extension of the project was titled Itinerant Dialogues as a way of stating, openly, the proposal to promote spaces of critical reflection on
\end{abstract}

\begin{abstract}
the interface between the knowledge of psychology and the issues of the present day that, in fact, are promoters of psychic suffering. occur through cycles of monthly lectures developed throughout the year in the UFC and in this educational public space of Fortaleza. These actions are guided by the laboratory's general annual research themes, in order to consolidate the linkage between teaching, research and extension. In the year 2018 the central theme has been "Loving Relationships", understanding that the panorama of "Liquid Modernity" crosses the phenomenon of love, as well as the very configuration of relationships in the actuality. The need to foster such practices as social inclusion and cultural diffusion, while maintaining closer ties with society, is emphasized.
\end{abstract}


KEYWORDS: Dialogues. Culture. Contemporaneity. Social inclusion.

\section{INTRODUÇÃO}

A base curricular do curso de Psicologia da UFC delineia uma formação generalista, de modo que o profissional de Psicologia possa dar continuidade à sua formação futura com segurança e autonomia, bem como atuar de forma competente e ética em diferentes áreas de sua abrangência profissional. Considerando essa conformação curricular, o discente que opta pela atuação profissional em psicologia muitas vezes não tem ao longo do curso oportunidades de vivenciar debates multiprofissionais em relação as ações e intervenções das práticas psicológicas na contemporaneidade bem como não se situa criticamente diante de discussões metodológicas referentes às diversas possibilidades de ensino e pesquisa no âmbito acadêmico. Os diversos laboratórios e núcleos que permeiam o curso de psicologia buscam especificar atuações práticas, estudar e aprofundar as teorias psicológicas, bem como realizar pesquisas e empreender projetos de ensino e de extensão que o que fazer acadêmico, comprometido com as disciplinas do núcleo comum, na maior parte das vezes, não consegue abranger. Mantendo-se permanentemente sensível às necessidades por parte dos discentes do curso de psicologia da UFC de aprofundamento e apropriação do saber/fazer psicológico em suas diferentes interfaces e campos de atuação, o projeto Diálogos em Psicologia surgiu em 2015 com o intuito de oferecer um espaço de crescimento e aprimoramento intelectual, de ampliação de conhecimentos teóricos e práticos no que concerne à clínica psicológica, contextualizadas às realidades sociais e às novas demandas sociais, não apenas para o meio acadêmico, mas, sobretudo, para comunidade em geral.

O projeto Diálogos em Psicologia, desde seu surgimento, no âmbito da UFC, mais especificamente, no Departamento de Psicologia, possui uma periodicidade mensal, sendo norteado por uma temática central, advinda das pesquisas desenvolvidas por projetos do Laboratório de Estudos em Psicoterapia, Fenomenologia e Sociedade (LAPFES) ao longo do ano. Desse modo, a comunidade em geral bem como os discentes/docentes passam a ter acesso aos estudos e pesquisas produzidos na universidade problematizando temáticas relevantes para o saber psicológico e sua articulação com as demandas contemporâneas.

Acreditando no propósito da disseminação de discussões contemporâneas como ferramenta cultural para o meio acadêmico e a comunidade em geral, o projeto Diálogos em Psicologia oferece ambientes problematizadores para a formação e cidadania levando o diálogo 
como inclusão social e difusão cultural em diferentes espaços. Problematizar assuntos contemporâneos que confluem para o debate acerca dos dilemas e as das questões sociais de nossa época, são uma convocação deste projeto por meio de suas articulações culturais tanto no âmbito da UFC como "Diálogos em Psicologia" e, externamente, desde 2016, como "Diálogos Itinerante em Psicologia" na EEFM Joaquim Moreira. Desta forma, se configurando como ações efetivas em ambos os espaços enquanto momentos de ampliação do conhecimento teórico e prático da psicologia em sua interface com demais campos do conhecimento.

A relevância do projeto Diálogos em Psicologia justifica-se tendo em vista a grandeza dos temas trazidos à discussão e compartilhados com a comunidade em geral que, muitas vezes, não tem a chance de aprofundar algumas das temáticas e práticas discutidas nos eventos, dadas as características da formação acadêmica generalista que norteiam os cursos de graduação em psicologia. Ademais, faz-se necessário levar em consideração o fato de que, muitas vezes, a comunidade acadêmica não tem a oportunidade de participar de quaisquer eventos, devido aos preços não cabíveis à parte financeira dos mesmos e, por isso, explicita-se a necessidade de exercício do projeto, como forma de inclusão social, difusão cultural e expansão do conhecimento, potencializando-se, assim, os sujeitos envolvidos no projeto Diálogos. Sendo assim, os eventos cumprem um papel essencial ao promover o desenvolvimento da Psicologia como ciência, na medida em que divulgam e produzem conhecimentos e na formação de psicólogos e competentes que pensam criticamente sua realidade.

O objetivo do projeto é promover discussões sobre os temas que atravessam a contemporaneidade, através de diferentes olhares da psicologia e de outros campos do conhecimento, construindo espaços horizontais que favoreçam a troca e a construção de diferentes saberes. No que concerne ao Diálogos itinerante esse objetivo se radicaliza, já que transpõe os muros das universidades e leva as discussões realizadas academicamente para outros espaços e públicos, na tentativa de honrar o compromisso social da universidade com a comunidade e com a possibilidade da construção de um saber vocacionado às necessidades e demandas atuais.

\section{REFERENCIAL TEÓRICO}

Para identificar os modos como a psicologia tem atuado no contexto contemporâneo reconhecemos a importância das influências históricas ao considerá-las de uma perspectiva diacrônica, no entanto sem desconsiderar que embora diversas mudanças e descobertas nesse campo 
tenham acontecido, desde os primeiros estudos e práticas, ainda assim a permanência de um modelo tradicional de psicologia constitui atualmente a maior parte das práticas desses profissionais da psicologia, no ensino e na formação.

Desse modo, cada vez mais faz-se necessário a ampliação da psicologia para além dos modelos convencionais, através do empenho na transformação de alguns paradigmas, tendo em vista principalmente as modificações das demandas culturais e sociais. Conforme Silva e Corgozinho (2011 apud Bernardes, 1998), o cenário mudou e a psicologia enquanto práxis se fortalece ao entender os tempos e os modos, para agir neles de maneira mais responsiva e efetiva a essas novas demandas, na perspectiva de um olhar sócio histórico.

Através das discussões promovidas por Eidelwein (2007) evidencia-se o valor da interdisciplinaridade nos contextos da psicologia ao considerar o surgimento da "necessidade de se aproximar de outras áreas do conhecimento, uma vez que historicamente a Psicologia se ocupou em estudar o indivíduo descontextualizado de suas relações sociais, culturais, econômicas e políticas" (EIDELWEIN; KAREN , 2007 p. 300). Assim a psicologia atualmente busca por meios diversos relacionar-se com os acontecimentos das esferas cotidianas, desagregando-se de antigas atribuições consideradas reducionistas e psicologizantes de um saber separado das realidades e das relações socioculturais que perpassam os indivíduos.

A ampliação da clínica surge como novidade para a psicologia, nessa conjuntura, junto com as percepções mais abrangentes das individualidades, ao considerar as influências histórico-sociais em cada sujeito e que isso não pode ser ignorado dentro dos âmbitos teóricos e práticos. Além do comprometimento político e social indispensável para um fazer crítico, trilhando rotas hodiernas, unindo saberes e estabelecendo teias de profissionais empenhados no desenvolvimento de dimensões mais agregadoras dos âmbitos das práticas psicológicas.

Considerando-se que em grande parte o contexto do sistema formador-universitário ainda se limita e insiste em permanecer conservador mediante novas propostas de intervenções menos generalistas, surgem algumas abrangências no que diz respeito às práticas psicológicas em suas dimensões teóricas, filosóficas e epistemológicas aumentando as possibilidades de expansão desses conceitos, mais aplicados em proporcionar o diálogo e a interdisciplinaridade.

A partir dessas compreensões é que o Projeto Diálogos em Psicologia se configura em espaços de formação e cidadania como meio de aprofundamento e apropriação dos conteúdos que sobrepuja os conhecimentos básicos e obrigatórios das grades curriculares, mas, além disso, a contextualização de assuntos contemporâneos em diferentes espaços dentro e fora da universidade, como é 
evidenciado no projeto Diálogos Itinerante em Psicologia onde ocorrem as discussões nos encontros planejados durante o ano em uma escola parceira.

O Projeto de extensão viabiliza problematizações contemporâneas levadas em diferentes espaços organizados para que muitas concepções teóricas e técnicas sejam repensadas, debatidas e futuramente modificadas. Para tanto evidencia-se a importante participação que inclua professores, alunos e a comunidade em geral interessada nesses processos ativos de construção de conhecimento, não somente voltado para os interesses institucionais ou mesmo individuais, mas sobretudo aos de valorização das influências e dos processos de caráter mais coletivo.

Mediante essas dimensões nota-se o papel fundamental da difusão cultural que impulsiona a inclusão social como ferramenta para a formação e a cidadania. Assim os laboratórios e núcleos dedicam-se a abertura e manutenção desses espaços mais implicados com os contextos socioculturais através da realização de pesquisas, da implementação de projetos de extensão e de ensino continuado, haja vista a necessidade de manter-se, enquanto projeto, em uma postura sensível e acolhedora das demandas sociais, favorecendo a manutenção de espaços reflexivos fomentadores de discussões que correspondam não só as necessidades dos discentes, mas que privilegiem uma formação menos exclusiva ao relacionar-se com a comunidade em geral.

Para o ano de 2018 a temática central de pesquisa do LAPFES e norteadora do projeto se configura em torno das discussões das Relações amorosas, mais precisamente, do amor romântico ao amor contemporâneo, tendo em vista a abrangência do assunto no decorrer do tempo, o Laboratório propôs estudar o assunto a partir de compreensões históricas, fazendo capturas para o contexto atual no que diz respeito aos novos modos de relações e como os mesmos implicam em rupturas com determinados modelos mais conservadores ao mesmo tempo que criam outros modelos e arranjos, como disse Bauman (2004) "No líquido cenário da vida moderna, os relacionamentos talvez sejam os representantes mais comuns, agudos, perturbadores e profundamente sentidos da ambivalência." (BAUMAN, 2004, p.8).

As transformações no modo como as pessoas se relacionam, no decorrer do tempo, podem ser visualizadas sob perspectivas de novos arranjos socioculturais, tendo em vista as influências diretas e indiretas da valorização do consumo, do hedonismo, dos fatores promotores de uma vida mais individualista, descomprometida e fluida. Portanto, no que diz respeito às pesquisas dessas relações, admite-se a qualidade de imprevisibilidade, que não se encaixa em categorias permanentes (BAUMAN, 2004, p.7), necessitando de um olhar abrangente, em constante adaptação e conectado para além do alcance das teorias psicológicas gerais. 
Desse modo, o projeto Diálogos em psicologia surge comprometido com o aprofundamento dos conhecimentos curriculares básicos e na propagação de práticas psicológicas inovadoras, assim como, com o empenho na compreensão dos fenômenos que compõem a sociedade de maneira inclusiva e mais acessível, em prol de um conhecimento de caráter mais social e interventivo. É nesses espaços de discussões que surgem oportunidades, inclusive, de combate às desigualdades sociais quanto a promoção de saúde mental por outras vias que enxergam para além da concepção saúde-doença, ao intervir em ações conjuntas que possibilitem novas elaborações e resoluções em relação aos sofrimentos psíquicos.

\section{MATERIAIS E MÉTODOS}

As atividades do projeto Diálogos em psicologia, mediante uma temática principal, associado às demandas da prática psicológica e das pesquisas desenvolvidas durante o ano, estruturam-se nos seguintes aspectos:

- Oportunizar espaços e eventos com diferentes temas que estabelecem relação teórica e prática no campo da psicologia e campos afins;

- Solicitar com antecedência a reserva do local onde ocorrem os eventos assim como estruturá-los previamente;

- Estabelecer parcerias institucionais para o diálogos itinerante;

- Através do contato com palestrantes ampliar as possibilidades de articulação entre conhecimentos acadêmicos;

- Promover a divulgação dos eventos por meio de mídias sociais e anúncios escritos e presenciais dentro das instituições;

- Realizar a elaboração e o envio dos certificados e declarações (por e-mail ou presencialmente) para os participantes e palestrantes compreendendo os informes necessários, fornecidas por eles.

Foram diversos os temas centrais trabalhados ao longo desses anos: em 2015 tivemos como tema a Medicalização da Vida, em 2016 a temática do corpo e seus dilemas na contemporaneidade, em 2017 a questão central foi a ditadura da felicidade e, neste presente ano, a questão das relações amorosas, podemos apresentar como temas de destaque nas ações deste ano os seguintes pontos: 
- Do amor romântico ao amor contemporâneo: Breve histórico;

- O amor e suas faces: Uma análise da fragilidade das relações humanas;

- Casar, namorar, ficar: Discussões contemporâneas;

- Relações abusivas: Quando estar com o outro é sinônimo de sofrimento;

- Amar, comprometer-se ou libertar-se: Uma discussão filosófica;

- Relações amorosas e sofrimento psíquico uma análise psicossocial

- Relações afetivas ou relações mercantilizadas?;

- Relações moduláveis: Relacionar-se na era virtual;

- Relações afetivas e seus diversos modos de expressão: Relatos de experiência.

\section{RESULTADOS E DISCUSSÕES}

Com base no trabalho empenhado, na produção de conhecimento e na ativa estruturação de novas práticas, o projeto de extensão Diálogos em Psicologia compromete-se em viabilizar o acesso e a contribuição nas discussões, aos discentes, docentes e outros interessados da comunidade em geral. Expandindo os contextos de formação ao não ignorar os processos sociais e constitutivos culturais para o desenvolvimento de perspectivas menos generalistas, ultrapassando assim os conceitos de uma formação centrada unicamente nos componentes curriculares obrigatórios, como também proporcionar com isso, espaços e discussões pertinentes para a contemporaneidade garantindo nesses processos a participação não só da comunidade acadêmica da UFC, mas de outras instituições formadoras e outras comunidades.

No ano de 2018 o Laboratório de Estudos em Psicoterapia, Fenomenologia e Sociedade (LAPFES) elegeu como temática principal de pesquisa as Relações Amorosas no Contemporâneo, sendo, esse mesmo tema, incorporado para o projeto Diálogos. É importante salientar que a escolha por essa temática de pesquisa não se deu ao acaso, mas pelo interesse dos membros por essas novas discussões, tendo em vista o número de casos que chegaram até a Clínica Escola de psicologia da UFC mediante demandas individuais e de grupo, que necessitam de uma escuta clínica sensível ao considerar outras perspectivas de vivências que acarretam sofrimentos psíquico, ligados às múltiplas questões das inter-relações construídas no cenário social atual. Assim, pensar as relações amorosas no contemporâneo é se debruçar na compreensão do modo como as pessoas desenvolvem sua afetividade e sua sexualidade para consigo e para com o outro, analisando aspectos constituintes do ser humano enquanto ser social e relacional. 
Como bem afirma Lins (2012), as relações amorosas descendem do contexto histórico e cultural no qual se inserem, sendo, portanto, modificadas a depender do período em questão. Na contemporaneidade, estando incluída a influência da mídia, há peculiaridades específicas e paradoxais nas relações amorosas, onde ora se deseja a liberdade e fluidez, características do contemporâneo, ora se deseja o amor romântico constitutivo de outros momentos históricos. Situando a psicologia como ciência integradora de posicionamento político firme e alinhada às demandas sociais, faz-se necessário entender o sofrimento que a vivência desse paradoxo gera nos processos de subjetivação dos sujeitos contemporâneos. Compreender e discutir essas relações como produtos de seu tempo, realizando as devidas comparações, destacando similaridades e diferenças é uma das justificativas para escolha dessa temática.

Desta forma, entendendo o projeto Diálogos como um espaço de difusão cultural, tanto na sua atuação dentro da universidade quanto na sua vertente itinerante, é compreensível o motivo de se trazer as discussões propostas na pesquisa para esse projeto, alinhando ambas as atividades. Como já foi exposto, o projeto Diálogos se constitui como um caminho de abertura para o desenvolver dessas discussões, comprometidas com temáticas de relevância contemporânea. Pensando numa psicologia contextualizada que recria formas de atuação fora dos panoramas reducionistas e buscando interlocuções com os diversos atores sociais; trabalhar as relações amorosas é possibilitar que os estudos, iniciados e desenvolvidos na pesquisa, reproduzam maiores resultados quanto à promoção e à difusão desse conhecimento em outros ambientes de acesso coletivo.

Vale ressaltar e destacar o protagonismo do projeto Diálogos nisso tudo, entendendo-o através de sua atuação promotora desses espaços de troca de conhecimento entre diversos atores sociais. O projeto Diálogos funciona como meio de difusão e discussão de temáticas que rodeiam as relações amorosas no cotidiano, fomentando momentos de implicação mútua e a construção de significados coletivos. Tal característica torna-se ainda mais evidente quando se pensa na vertente Itinerante do projeto, onde as discussões transcendem os muros universitários, alcançando o público adolescente dentro da escola. Proporcionar espaços onde esses jovens possam se posicionar a respeito dessas questões e convidá-los a refletirem sobre suas próprias experiências, e como elas são permeadas por características do contexto contemporâneo.

\section{CONSIDERAÇÕES FINAIS}


A Psicologia é constituída por diversos olhares teóricos, filosóficos e epistemológicos, fonte onde surgem as mais diversificadas práticas psicológicas. Práticas essas que necessitam estar atentas às novas demandas que emergem no contexto contemporâneo para oferecer intervenções situadas na realidade dos sujeitos. Dessa forma, alunos e profissionais precisam estar em constante formação e reciclagem.

Assim, o Projeto Diálogos em Psicologia consiste em uma ação de extensão que visa promover espaços de discussão e trocas entre os vários saberes da psicologia, com o intuito de difundir e construir novas formas de manejar as problemáticas contemporâneas, além de levar a problematização de tais questões para o extramuros da universidade, confirmando, sobretudo, uma relação mais próxima e democrática com a comunidade.

Tem-se como cultura um amplo conjunto de costumes, valores, práticas e modos de se colocar no mundo. As construções culturais estão intimamente ligadas ao modo como os sujeitos encaram e vivenciam sua sociedade, por isso discutir as novas formas de subjetivação diante das problemáticas concernentes à cultura atual é extremamente importante.

O projeto Diálogos busca sustentar a tríade que a universidade desenvolve que é o ensino, a pesquisa e a extensão, trazendo sempre em voga os temas estudados em pesquisa pelo laboratório. O projeto visou, durante todos esses anos, lançar um olhar crítico sobre a formação em Psicologia, promover espaços de rearticulação da produção do saber, ofertar debates acerca da interface da Psicologia e demais campos do conhecimento e, por fim, refletir sobre o papel da Psicolgia diante das atuais questões sociais e culturais.

\section{REFERÊNCIAS}

BAUMAN, Z. Amor líquido: Sobre a fragilidade dos laços humanos. Rio de Janeiro: Zahar, 2004. Tradução de: Carlos Alberto Medeiros

EIDELWEIN, K. (2007). Psicologia social e serviço social: uma relação interdisciplinar na direção da produção de conhecimento. Revista Virtual Textos \& Contextos, 8, 298-313.

GAMA, C. A. P. \& KODA, M. Y. (2008). Psicologia comunitária e Programa de Saúde da Família: relato de uma experiência de estágio. Psicologia Ciência e Profissão, 28(2), 418-429.

LINS, R. N. O livro do amor, volume 1: da Pré-história à Renascença. Rio de Janeiro: Best Seller, 2012. 
SILVA, J. V.; CORGOZINHO, J. P. Atuação do psicólogo, SUAS/CRAS e Psicologia Social Comunitária: possíveis articulações. Psicol. Soc., Florianópolis, v. 23, p.12-21, 2011. Disponível em:<http://www.scielo.br/scielo.php?pid=S0102-

$71822011000400003 \&$ script=sci_abstract\&tlng=pt $>$. Acesso em: 02/09/2018. 